\title{
What are the risk factors for admission to the pediatric intensive unit among pediatric patients with COVID-19?
}

\author{
Susanna Esposito ${ }^{* *}$, Fabio Caramelli ${ }^{2}$ and Nicola Principi ${ }^{3}$
}

\begin{abstract}
Background: Although with exceptions, evidence seems to indicate that children have lower susceptibility than adults to severe acute respiratory syndrome coronavirus 2 (SARS-CoV-2) infection. When infected, children generally remain asymptomatic or develop mild disease. A small number of pediatric cases required admission to the pediatric intensive care unit (PICU), respiratory support with a mechanical ventilation and additional life-saving interventions. Even if rarely, death can occur. Aim of this manuscript is to highlight the risk factors associated with severe outcome among pediatric patients with COVID-19.

Main findings: Early identification of SARS-CoV-2-infected children at risk of developing severe COVID-19 is vital for service planning, as severely affected pediatric patients require high-quality care and should be followed only where an adequately structured PICU is available. However, early identification of children who must be carefully monitored for substantial risk of severe COVID-19 remains difficult. An underlying comorbidity and heart involvement are frequently observed in severe paediatric cases. Reduced left ventricular systolic function with an ejection fraction <60\%; diastolic dysfunction; and arrhythmias, including ST segment changes, QTc prolongation, and premature atrial or ventricular beat, are the earliest manifestations of heart involvement. Inclusion of heart enzyme serum levels and evaluation of ventricular function among predictive markers could lead to a more effective evaluation of children at risk with proper selection of those to admit to the PICU and with more adequate treatment in case of more severe clinical manifestations.

Conclusions: To appropriately manage severe pediatric COVID-19 cases, greater attention should be paid to risk factors in children and adolescents, especially to cardiovascular alterations (e.g., heart enzyme serum levels and evaluation of ventricular function). Further studies are needed and the development of a validated score based on all the most common presumed markers of disease severity seems essential.
\end{abstract}

Keywords: Children, COVID-19, Pediatric intensive care unit, SARS-COV-2

\footnotetext{
* Correspondence: susanna.esposito@unimi.it

${ }^{1}$ Pediatric Clinic, Department of Medicine and Surgery, University Hospital, University of Parma, Pietro Barilla Children's Hospital, Via Gramsci 14, 43126 Parma, Italy

Full list of author information is available at the end of the article
}

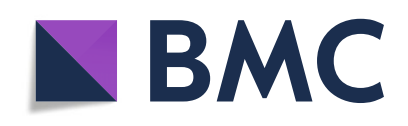

(- The Author(s). 2021 Open Access This article is licensed under a Creative Commons Attribution 4.0 International License, which permits use, sharing, adaptation, distribution and reproduction in any medium or format, as long as you give appropriate credit to the original author(s) and the source, provide a link to the Creative Commons licence, and indicate if changes were made. The images or other third party material in this article are included in the article's Creative Commons licence, unless indicated otherwise in a credit line to the material. If material is not included in the article's Creative Commons licence and your intended use is not permitted by statutory regulation or exceeds the permitted use, you will need to obtain permission directly from the copyright holder. To view a copy of this licence, visit http://creativecommons.org/licenses/by/4.0/. The Creative Commons Public Domain Dedication waiver (http://creativecommons.org/publicdomain/zero/1.0/) applies to the data made available in this article, unless otherwise stated in a credit line to the data. 


\section{Background}

Although with exceptions, evidence seems to indicate that children have lower susceptibility than adults to severe acute respiratory syndrome coronavirus 2 (SARSCoV-2) infection [1-3]. When infected, children generally remain asymptomatic or develop mild disease [4]. A joint report from the American Academy of Pediatrics and the Children's Hospital Association indicated that on January 28, 2021, a total of 2,816,775 COVID-19 cases in children have been reported in the USA; a value that represents only $12.8 \%$ of cases in the USA and $1.2-$ $2.9 \%$ of hospitalizations associated with the disease [5]. In the reporting states, child mortality accounted for $0.00-0.21 \%$ of COVID-19 deaths [5]. A small number of pediatric cases required admission to the pediatric intensive care unit (PICU), respiratory support with a mechanical ventilation and additional life-saving interventions. Even if rarely, death can occur. A multinational, multicenter cohort study carried out in Europe showed that among 582 children with laboratoryconfirmed SARS-CoV-2 infection and a median age of 5.0 years, $62 \%$ were hospitalized, $8 \%$ required admission to the PICU, $5 \%$ had radiological findings suggestive of acute respiratory distress syndrome and $4 \%$ were intubated and mechanically ventilated [6]. Fatal outcomes occurred in 4 cases [6]. In a recent multicentre Italian study aimed at investigating epidemiological, clinical and therapeutic aspects of SARS-CoV-2 infection in infants, children and adolescents, $149 / 759$ children $(19.6 \%$ of the entire study population and $38.8 \%, 140 / 361$, of those hospitalized for COVID-related causes) developed one or more complications [7]. Mean age was significantly higher among children with complications than in uncomplicated infections (6.9 vs. 5.5 years, respectively; $p=0.023$ ), while gender was non-contributory to complications development. At multivariate analysis, fever or abdominal pain at onset and co-morbidities were risk factors for complications. Thirty children (4.0\%) required intensive care support for COVID-19. Viral coinfections, underlying clinical conditions and age between 5 and 9 years were statistically related to PICU admission [7]. No information is available on chronic diseases most at risk of a serious course of the disease. No association was found with gender, ethnicity and socio-economic factors. Differences between the studies in hospitalization and PICU admission rates seem related mainly to protocols or clinical practice and not necessarily to disease severity. As regards hospitalized pediatric cases and those admitted to PICU, given the scarcity of data available in the literature, we recently highlighted that it would be advisable for pediatricians to identify a set of variables to be monitored over time using a shared methodology and definitions [8]. Aim of this manuscript is to highlight the risk factors associated with severe outcome among pediatric patients with COVID-19.

\section{Importance of early identification of pediatric patients with COVID-19 at risk of severe outcome}

Early identification of SARS-CoV-2-infected children at risk of developing severe COVID-19 is vital for service planning, as severely affected pediatric patients require high-quality care and should be followed only where an adequately structured PICU is available. Hospitalization of children at risk in properly equipped units before the development of severe clinical manifestations seems essential to improve disease outcome, reducing the need for invasive treatment, duration of hospital stay, and risk of death [6].

\section{Risk factors associated with severe outcome among pediatric patients with COVID-19}

In adults with COVID-19, it has been observed that independent risk factors associated with mortality included older age, male sex, high fraction of inspired oxygen, high positive end-expiratory pressure, and history of chronic obstructive pulmonary disease, hypercholesterolemia, and type 2 diabetes $[9,10]$. Studies that have evaluated which factors could predict severe pediatric COVID-19 have shown that younger age, pre-existing underlying chronic severe comorbidities, male sex and lower respiratory tract infection signs and symptoms at presentation could be considered risk factors for PICU admission [11-13]. Among laboratory markers, increased leukocyte count, lymphopenia, and elevated inflammatory markers (C-reactive protein and procalcitonin) were those more frequently associated with PICU admission [11-13]. Only in some cases were lactate dehydrogenase, pro-B-type natriuretic peptide and troponin studied and found to be increased, suggesting a potential role of these variables as markers of risk.

Despite these findings, early identification of children who must be carefully monitored for substantial risk of severe COVID-19 remains difficult. Definitive conclusions about the real role of the suggested risk markers as predictors of severity cannot be drawn, as most of the studies have enrolled few patients [6-8]. Additionally, the criteria used for enrollment and evaluation differed significantly. The lack of a cutoff level for some parameters does not allow us to establish which patients are truly at risk. Regarding the role of age, there were large differences among studies. In some cases, it was reported that children $\leq 1$ year old were at risk, whereas in others, only children $\leq 1$ month old had a greater probability of developing severe disease [6-8]. Most cases of multisystem inflammatory syndrome in children (MIS-C), one of the most severe clinical manifestations of pediatric COVID-19, occur in school-age patients and have 
marginal epidemiological importance in younger children [14]. The presence of an underlying chronic disease in children admitted to the PICU has been documented in several studies and is generally considered the most reliable marker of severe COVID-19 in pediatrics [6]. However, the prevalence of these factors among PICU patients varies significantly. In some studies, the prevalence of comorbidities was documented in more than $70 \%$ of children with severe disease [15]. In a European study, only $52 \%$ of PICU cases had an underlying disease [6]. This conflicting evidence suggests that, if an underlying comorbidity may be a risk factor for severe COVID-19 in children, it is not the only factor capable of favoring the worsening of the clinical picture and the development of complications.

More effective identification of at-risk children could be obtained if several variables could be simultaneously considered, and a risk score could be developed. A similar solution was found to be effective in adults by Liang et al. [16] Starting with 72 variables characterizing COVID-19 adult patients, they identified 10 independent predictors of severe or critical disease. With a mathematical model, a well-defined value was attributed to each variable, and a score was developed [16]. Later, it was validated to show high efficacy in predicting a patient's risk of developing critical illness. However, to prepare a pediatric score, criteria for admission to the PICU must be clarified, including the degree of respiratory impairment and cutoff levels of laboratory tests. The inclusion of potential markers of severity to date have been poorly considered, must be evaluated. Among these is heart involvement [16]. Several findings seem to indicate that, in the first phases of severe COVID-19, signs and symptoms of heart lesions can occur and be useful to select children at risk for complications [13, 17, 18]. A great number of previously healthy children with MIS-C present with cardiovascular alterations [19-21]. Some of them already have signs and symptoms of heart dysfunction in the first phases of disease, and it has been reported that they increase the need for PICU admission, development of potential long-term problems, and risk of death [13, 17, 18]. Reduced left ventricular systolic function with an ejection fraction $<60 \%$; diastolic dysfunction; and arrhythmias, including ST segment changes, QTc prolongation, and premature atrial or ventricular beat, were the earliest manifestations. Moreover, increased troponin levels have been repeatedly reported in children with COVID-19 admitted to the PICU [13, 18, 19]. Inclusion of heart enzyme serum levels and evaluation of ventricular function among predictive markers could lead to a more effective evaluation of children at risk with proper selection of those to admit to the PICU and with more adequate treatment in case of more severe clinical manifestations.

\section{Conclusions}

The criteria for admission to a PICU for the SARS-CoV2-positive patient are not different from the general admission criteria for non-positive pediatric patients and are represented by the direct consequences of the viral infection (generally severe respiratory failure), by the complications of the infection (e.g., MIS-C) and by the onset, concomitantly with SARS-CoV-2 infection, of other conditions for which hospitalization is indicated $[8,20]$. In addition, it will also be necessary to ensure a specific intensive track that ensures proper isolation, as well as the adoption of the appropriate safety devices by patients and their caregivers, in order to avoid dangerous cross-infections between patients and patients, and between patients and health care workers, according to international standards redefined on the basis of local policies [21]. Table 1 summarizes the recommendations that we developed for considering admission to the PICU in the Emilia-Romagna Region, Italy. To appropriately manage severe pediatric cases, greater attention should be paid to risk factors in children and adolescents, especially to cardiovascular alterations (e.g., heart

Table 1 Recommendations for considering admission to the pediatric intensive care unit (PICU) in the Emilia-Romagna Region, Italy

When is it recommended to admit a pediatric patient to the PICU?

In case of the need for CPAP in the COVID-positive patient in acute respiratory failure, hospitalization in a referral center equipped with a PICU is recommended.

Hospitalization in the PICU is recommended in case of the following:

-Tachypnea associated with at least one of the following signs or symptoms: dyspnea, elevated work of breathing, cyanosis, hypoxia and/or desaturation, inability to eat and drink, lethargy,

unconsciousness or convulsions;

-Acute respiratory distress syndrome $(\mathrm{PaO} 2 / \mathrm{FiO} 2 \leq 300$ in bilevel or CPAP $\geq 5 \mathrm{~cm} / \mathrm{H}_{2} \mathrm{O}$ );

-Need for inotropic support and/or hemodynamic monitoring; -Instability, cardiocirculatory insufficiency or any condition of shock;

-Multiorgan failure;

-Severe sepsis;

-Coma.

What are the risk factors for admission to the PICU?

-Presence of new onset left ventricular dysfunction, coronary abnormalities or pericardial effusion on echocardiography;

-Deterioration of laboratory tests (C reactive protein, procalcitonin, interleukin-6, ferritin, D-dimer, troponin, liver indices, and lactate dehydrogenase);

-Progressive respiratory failure: failure to reduce heart rate, respiratory rate and work of breathing and failure to improve $\mathrm{O}_{2}$ saturation, 30 min and $2 \mathrm{~h}$ from the start of high flow therapy are highly predictive of noninvasive ventilation failure, as well as elevated PRISM values basal, $\mathrm{CO}_{2}$ and $\mathrm{FiO}_{2}$.

CPAP Continuous Positive Airway Pressure, PRISM Pediatric Risk of Mortality Score 
enzyme serum levels and evaluation of ventricular function). Further studies are needed and the development of a validated score based on all the most common presumed markers of disease severity seems essential.

\section{Abbreviations}

COVID-19: New coronavirus disease 2019; CPAP: Continuous Positive Airway Pressure; MIS-C: Multisystem inflammatory syndrome in children; PICU: Pediatric Intensive Care Unit; PRISM: Pediatric Risk of Mortality Score; SARS-CoV-2: Severe acute respiratory syndrome coronavirus

\section{Acknowledgements}

We would like to thank the COVID-19 Working Group in Pediatrics of the Emilia-Romagna Region (RE-Co-Ped), Italy, for the useful discussions on COVID-19 management.

\section{Authors' contributions}

SE and NP co-wrote the manuscript, FC gave a substantial scientific contribution. All the authors approved the final version of the manuscript.

\section{Funding}

This manuscript was supported by a research grant from the Department of Medicine and Surgery, University of Parma, Parma, Italy.

\section{Availability of data and materials}

All included.

\section{Declarations}

Ethics approval and consent to participate

Not applicable.

\section{Consent for publication}

Not applicable.

\section{Competing interests}

The authors declare no competing interest.

\section{Author details}

${ }^{1}$ Pediatric Clinic, Department of Medicine and Surgery, University Hospital, University of Parma, Pietro Barilla Children's Hospital, Via Gramsci 14, 43126 Parma, Italy. ${ }^{2}$ Paediatric Intensive Care Unit, Scientific Institute for Research and Healthcare (IRCCS) Azienda Ospedaliero-Universitaria di Bologna, Bologna, Italy. ${ }^{3}$ Università degli Studi di Milano, Milan, Italy.

Received: 17 March 2021 Accepted: 26 April 2021

Published online: 03 May 2021

\section{References}

1. Viner RM, Mytton OT, Bonell C, Melendez-Torres GJ, Ward J, Hudson L, et al. Susceptibility to SARS-CoV-2 infection among children and adolescents compared with adults: a systematic review and meta-analysis. JAMA Pediatr. 2021;175(2):143-56. https://doi.org/10.1001/jamapediatrics.2020.4573.

2. Cusenza F, Davino G, D'Alvano T, Argentiero A, Fainardi V, Pisi G, et al. Silence of the lambs: the immunological and molecular mechanisms of COVID-19 in children in comparison with adults. Microorganisms. 2021;9(2): 330. https://doi.org/10.3390/microorganisms9020330.

3. Li F, Li YY, Liu MJ, Fang LQ, Dean NE, Wong GWK, et al. Household transmission of SARS-CoV-2 and risk factors for susceptibility and infectivity in Wuhan: a retrospective observational study. Lancet Infect Dis. 2021: S1473-3099(20):30981-6.

4. Vergine G, Fantini M, Marchetti F, Stella M, Valletta E, Biasucci G, et al. Home management of children with COVID-19 in the Emilia-Romagna Region, Italy. Front Pediatr. 2020;8:575290.

5. American Academy of Pediatrics. Children and COVID-19: state-level data report. Available at: https://downloads.aap.org/AAP/PDF/AAP\%20and\%2 0CHA\%20-\%20Children\%20and\%20COVID-19\%20State\%20Data\%2 OReport\%201.28.21\%20FINAL.pdf Accessed 4 Feb 2021.

6. Götzinger F, Santiago-García B, Noguera-Julián A, Lanaspa M, Lancella L, Calò Carducci Fl, et al. COVID-19 in children and adolescents in Europe: a multinational, multicentre cohort study. Lancet Child Adolesc Health. 2020; 4(9):653-61. https://doi.org/10.1016/\$2352-4642(20)30177-2.

7. Garazzino S, Lo Vecchio A, Pierantoni L, Calò Carducci Fl, Marchetti F, Meini A, et al. Epidemiology, clinical features and prognostic factors of pediatric SARS-CoV-2 infection: results from an Italian multicenter study. Front Pediatr. 2021;9:649358.

8. Esposito S, Marchetti F, Lanari M, Caramelli F, De Fanti A, Vergine G, et al. COVID-19 Management in the Pediatric age: consensus document of the COVID-19 working Group in Paediatric sof the Emilia-Romagna region (RECO-Ped), Italy. Intern J environ res. Public Health. 2021;18:8.

9. Grasselli G, Zangrillo A, Zanella A, Antonelli M, Cabrini L, Castelli A, et al. Pesenti a; COVID-19 Lombardy ICU network. Baseline characteristics and outcomes of 1591 patients infected with SARS-CoV-2 admitted to ICUs of the Lombardy region, Italy. JAMA. 2020;323(16):1574-81. https://doi.org/10.1 001/jama.2020.5394.

10. Grasselli G, Greco M, Zanella A, Albano G, Antonelli M, Bellani G, et al. COVID-19 Lombardy ICU Network. Risk Factors Associated With Mortality Among Patients With COVID-19 in Intensive Care Units in Lombardy, Italy. JAMA Intern Med. 2020;180(10):1345-55.

11. Tsabouri S, Makis A, Kosmeri C, Siomou E. Risk factors for severity in children with coronavirus disease 2019: a comprehensive literature review. Pediatr Clin N Am. 2021:68(1):321-38. https://doi.org/10.1016/.jpcl.2020.07.014.

12. Siebach MK, Piedimonte G, Ley SH. COVID-19 in childhood: Transmission, clinical presentation, complications and risk factors. Pediatr Pulmonol. 2021. https://doi.org/10.1002/ppul.25344.

13. Pokorska-Śpiewak M, Talarek E, Popielska J, Nowicka K, Ołdakowska A Zawadka K, et al. Comparison of clinical severity and epidemiological spectrum between coronavirus disease 2019 and influenza in children. Sci Rep. 2021;11(1):5760. https://doi.org/10.1038/s41598-021-85340-0.

14. Esposito S, Principi N. Multisystem inflammatory syndrome in children related to SARS-CoV-2. Paediatr Drugs. 2021;22:1-11.

15. Shekerdemian LS, Mahmood NR, Wolfe KK, Riggs BJ, Ross CE, McKiernan CA, et al. Characteristics and outcomes of children with coronavirus disease 2019 (COVID-19) infection admitted to US and Canadian pediatric intensive care units. JAMA Pediatr. 2020;174(9):868-73. https://doi.org/10.1001/jama pediatrics.2020.1948

16. Liang W, Liang $\mathrm{H}, \mathrm{Ou} \mathrm{L}$, Chen B, Chen A, Li C, et al. Development and validation of a clinical risk score to predict the occurrence of critical illness in hospitalized patients with COVID-19. JAMA Intern Med. 2020;180(8):10819. https://doi.org/10.1001/jamainternmed.2020.2033.

17. Abrams JY, Oster ME, Godfred-Cato SE, Bryant B, Datta SD, Campbell AP, et al. Factors linked to severe outcomes in multisystem inflammatory syndrome in children (MIS-C) in the USA: a retrospective surveillance study. Lancet Child Adolesc Health. 2021;S2352-4642(21):00050-X. https://doi. org/10.1016/S2352-4642(21)00050-X.

18. Feldstein LR, Tenforde MW, Friedman KG, Newhams M, Rose EB, Dapul H, et al. Characteristics and outcomes of US children and adolescents with multisystem inflammatory syndrome in children (MIS-C) compared with severe acute COVID-19. JAMA. 2021;325(11):1074-87. https://doi.org/10.1 001/jama.2021.2091.

19. Hoste L, Van Paemel R, Haerynck F. Multisystem inflammatory syndrome in children related to COVID-19: a systematic review. Eur J Pediatr. 2021:1-16. https://doi.org/10.1007/s00431-021-03993-5.

20. Kache S, Chisti MJ, Gumbo F, Mupere E, Zhi X, Nallasamy K, et al. COVID-19 PICU guidelines: for high- and limited-resource settings. Pediatr Res. 2020; 88(5):705-16. https://doi.org/10.1038/s41390-020-1053-9.

21. Walker DM, Tolentino VR. COVID-19: the impact on pediatric emergency care. Pediatr Emerg Med Pract. 2020;17(Suppl 6-1):1-27.

\section{Publisher's Note}

Springer Nature remains neutral with regard to jurisdictional claims in published maps and institutional affiliations. 